\title{
Research and Analysis on Positioning of Project Supervision in China
}

\author{
Jiading Wang \\ City construction department \\ Xinjiang Vocational and Technical College of Construction \\ Urumqi, 830026, China \\ Email:773573713@qq.com
}

\begin{abstract}
Keywords: Project Supervision; Positioning; Supervision Engineer; FIDIC
Abstract. The paper looks back the history background in which project supervision system occurred, illustrates the function of the project supervision. Then, while affirming the achievement that the project supervision work has got, combining the real situation of the project supervision, the paper widely and deeply analyzes some problems and deep-seated contradiction in the theory and practice of project supervision. For character of project supervision, range of project supervision stage, the paper makes comparison and research from theory to practice, from our nation to the world, and presents the suggestions and opinions.
\end{abstract}

\section{Preface}

Implementing the project supervision system is an important reform measure of construction management system in our country, a kind of necessity that the planning economy transmits to the market economy and also a demand that the system adapts to the international market and international construction regulation. After more than $t$ years of implementing, the project supervision system, the project construction has got a conspicuous achievement.

However, some problems of deep layer in the field have gradually emerged while the project supervision obtains the achievements which are great difference between the project supervision and original intention of implanting the project supervision system, great difference between the project supervision theory and practice, etc. Regarding all these questions, the thesis look backs the development process of the project supervision, points out the problems of the project supervision, researches how to recognize the positioning of the project supervision correctly and enhance the development of the project supervision.

The section headings are in boldface capital and lowercase letters. Second level headings are typed as part of the succeeding paragraph (like the subsection heading of this paragraph).

\section{Character of project supervision}

Which part the project Supervision Engineer is on behalf of has not been explained well until now. Firstly, the clause 32 of Construction law, issued on July 1, 2011 pointed out that the project Supervision Engineer shall supervise the contractor in the aspect of construction quality, period and fund use on behalf of owner according to the law, administrative regulation, standard, designs and construction contract. Obviously, according to the "Construction law", the Supervision Engineer represents owner. But according to the item 18 of Project Supervision Regulation(No 737) and item 1.0.9 of general of Construction Project Supervision Specification(GB50319-2013), the project supervision enterprise shall implement the supervision work according to the principle "fair, independence and self determination”. As per this supervision specification and standard, the Supervision Engineer should belong to the third party. Due to inconsonance of the law, standard and regulations related to the project supervision, the Supervision Engineer can not be independent in legal principle while implementing the supervision work, especially dealing with the contract management and project claim. Independence is premise of fairness. If the Supervision Engineer can not implement the supervision work independently, where is fairness? Secondly, the Supervision 
Engineer implements the work entrusted by the owner, so one of the important features of the project supervision is its "service" and the service object is owner. Therefore, the Supervision Engineer should maintain the interest of the owner. Thirdly, Supervision Engineer should be paid by the service object which is owner. So, the Supervision Engineer dare not directly or publicly breach their willing whatever owner is right or not. In such case, how the Supervision Engineer implement their job fairly?

When the current textbook ----General of Construction Project Supervision illustrates" Fairness", it adopts more obscure language which is the project enterprise shall eliminate all disturbances during course of implementing the project supervision, treat owner and contracting company objectively and fairly. Especially when the conflicts or contradiction occurred from both parties, the project Supervision Engineers shall not damage the legal interest of the contracting company when maintaining the legal interest of owner basing on the truth, law and the related contract. For an example, when mediating the disputes between owner and contracting company, dealing with project claim and project delay, implementing payment control of project fund and project completion settlement, the project Supervision Engineer shall treat owner and contracting company objective and fair as possible ${ }^{[4]}$. What is "as objective and fair as possible"? Why "fairness and objectivity" still have space? So, when the author illustrates "independence and fairness" of project supervision, he also tastes the situation of the Supervision Engineer.

Engineering Construction Supervision Regulations requires that the project supervision enterprise implement supervision work as per the principle of 'fairness, independence and self-determination' which used relevant clause of famous first edition of FIDIC Civil Engineering Construction Conditions issued by FIDIC in 1957. The book has been revised for four times, but maintained an important principle which requires engineers to deal with relevant problems of the contract. This principle constitutes an important feature of the supervision system and also one of FIDIC foundations, which is the original basis of 'impartiality, independence and self determination' on which the Engineers implements work ${ }^{[5]}$. However, in the latest edition of FIDIC Constitution of Contract for Construction 1999, there is new explanation on the definition of employer's personnel which clarifies that Engineer, his assistant, other staff, workers and employees of the owner all belong to the owner rather than stresses that the Engineer is an independent party ${ }^{[6]}$. When the Engineer makes a decision on something, impartiality is not stressed but fair. Impartiality can be understood as impartial without deflection. But since the Supervision Engineer is hired by the employer, it is impossible for Supervision Engineers to be impartial without any deflection but fair, which is also the most criticism that the FIDIC heard when he investigated and practiced the old edition. The Engineer is entrusted to execute contract management and receive owner's rewards, so he can not act as a referee or arbitrator. In general conditions, DAB clause is added and the rewards of DAB personnel are undertaken by owners and contractors evenly. Therefore, the behavior and decisions of DAB personnel shall obey the principle of impartiality and Independence. During the initial stage of project supervision system implementation, no matter what it is impossible in aspect of theory or practice to introduce such system and restrict system of the third party to make supervision engineers deal with disputes between owners and contractors.

According to above analysis and positioning of Engineer by FIDIC, the feature of Supervision Engineer in our country shall be repositioned. Firstly, Supervision Engineer and his project agency is no longer an independent party, they are the relevant staff of owners in project management. However, the supervision enterprise is an independent legal man, and signs supervision contract with owners as independent legal man, as soon as contracts are signed and supervision organization and agency are set up, the supervision staff of the supervision agency, including Engineer, shall sincerely service owners, no longer an independent party. Implementing supervision work impartially and objectively is no longer legal obligation of supervision staff but his morality rule. Namely when the supervision engineer executes contract management, he shall implement supervision task basing on law and contract. When disputes arise from owners and contractors, the supervision engineer is no longer acting as referee, and arbitration agency shall mediate and settle the disputes. Overseas, DAB mediate and settle disputes from owners and contractors while in our country, a similar arbitration 
agency within architecture association society shall mediate and deal with disputes between owners and contractors.

\section{Phase range of project supervision}

The project supervision range in China refers to the whole procedure or only limited to the construction stage is a problem to puzzle supervision system for many years. According to supervision theory and Project Supervision Regulation and Construction project Supervision Specification, the supervision range shall refers to the whole procedure. However, in June, 2005, during the national project supervision conference held in Dalian, leader Miss Wang Suqin pointed that the supervision range in our country is only limited to construction stage whose basis is clause 32 of Construction Law, Namely, Supervision Engineer shall implement supervision on the construction quality, construction period and construction fund according to the law, regulation and technical standard, design document and construction contract on behalf of owners. However, the paper argues that Construction Law doesn't clarify the supervision working range only confirm compulsive supervision range is the construction stage. Although application range of Construction Project Supervision Specification refers to the construction stage, however, as mentioned in the preface 'whereas supervision work in the investment and design stage has not formed systematic and mature experience, a further research through practice is needed. Therefore, the specification doesn't involve the supervision work in feasible study and design stage.'

The latest training textbook, such as Investment Control of Construction Project, Quality Control of Construction Project and Progress Control of Construction Project for supervision engineer test, all compile a chapter on design supervision. Contract Management of Construction Project also includes supervision content in tender stage. Investment Control of Construction Project includes all content of supervision which is investment control in decision stage, design stage, tender stage and construction stage.

It does not deny that at present most project supervision work is only limited to the construction stage. According to the investigations on 172156 supervision projects in such cities or provinces as Beijing, Shanghai, Jiangsu, etc, the distribution proportion of supervisions work except in construction stage is as follows: $1.39 \%$ for preliminary period consultation, $0.85 \%$ for design tender, $0.48 \%$ for reconnaissance supervision and $2.53 \%$ for design supervision during the recent three years. There are many reasons to cause such phenomenon Firstly, the forcible stage that requires supervision in China is the construction stage. Secondly, during recent years, salary for the Supervision Engineers is very little; supervision industry can not attract talents with preliminary consultation and design knowledge. Besides, some owners did not notice the importance of the supervision. They accepted supervision, but they did not give positive match and support, plus irregular operation of construction market, the supervision work did not run in the specific orbit. Therefore, supervision work has always hesitated in a low level, and not extended to design and preliminary consultation stage. However, the paper suggests the law and legislation system for guiding supervision industry should be in accordance with theory system.

Whether the supervision work shall be applied to the construction stage or the whole stage is still be argued in China. The paper maintains that the supervision work shall be applied to the whole stage. Firstly, that the project supervision shall be applied to the construction stage is conflict with the present supervision theory. Secondly, applying the project supervision only to the construction stage doesn't facilitate the investment, quality and progress control of construction project entirely. For an example, when a civil engineering doctor is in the position of vice director in Zhengzhou municipal construction committee, he present his doubt to the design plan of an international master, after the plan was revised, RMB 100 million investment was saved. Besides, the design stage also affects the project quality. According to the incomplete statistics, $60 \%$ of project quality accidents are related to the construction while $40 \%$ of them are related with design. Although, many drawing reviewing company in most provinces will approve the drawing quality, they only implement final control rather than the whole stage supervision. In addition, progress in the construction stage is also closely 
connected with the design. Some design drawing is not checked and reviewed and modification is very frequently in the construction stage so that the construction progress control is seriously affected. Thirdly, applying the project supervision in construction stage can not match the international regulation. It is well known why the supervision system in China is introduced from aboard is suitable for foreign market and match with international management. Fourth, many owners do not know the professional knowledge, even the project budget staff do not grasp the professional theory related to the design, therefore, they can not present feasible suggestion to the structure design plan of design people but abide to them. More and more owners have realized this point.

\section{Conclusions}

With the end of transient period of joining WTO, the competition regulation, technical standard, operation style and service model will gradually match with the world, the development of project supervision has come to the crossroad and the project supervision enterprise also encounter the opportunity and challenge. Where the project supervision shall be going is a serious problem facing the government and all of us. The actual situation indicated that independence and impartiality is suspected and lack of foundation base and practice test. Limiting of supervision stage will not facilitate development and perfection of supervision system, nor abide by supervision principle. The paper suggests that the relevant government department shall complete the project supervision principle. Firstly, the project supervision character shall be repositioned, the "independence " and "impartiality" are unnecessary to be emphasized any more with "science, abiding law, service and credit" replaced; secondly, the supervision work in construction stage shall be extended to the design stage. Basing on absorbing the experiences and lessons of supervision work in construction stage, the government shall issue the law, regulation, standard and specification related to the design supervision and design supervision gradually is implemented.

\section{References}

[1] People's Republic of China Construction Law. 2011.

[2] People's Republic of China standard, Engineering Construction Supervision Regulations (No. 735), 1995.

[3] People's Republic of China standard, Supervision code for Construction Engineering (GB50319-2013), Beijing China Building Industry Press. 2013

[4] National supervision engineer training materials Committee, General of Construction Project Supervision, Beijing: China Building Industry Press, 2013.

[5] Guide to the use of FIDIC 1987.

[6] FIDIC Constitution of Contract for Construction 1999.

[7] National supervision engineer training materials Committee. Progress control of construction project, Beijing: China Building Industry Press, 2013. 